\title{
A formação profissional crítica em Serviço Social inserida na ordem do capital monopolista
}

\author{
Critical professional background in Social Services \\ within the monopolistic capital order
}

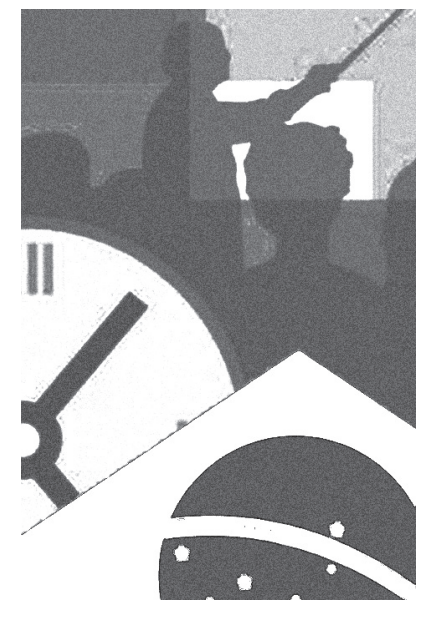

Ricardo Silvestre da Silva*

Resumo: O texto que segue trata sobre as transformações que vêm ocorrendo no ensino superior brasileiro a partir da última década, e como as mesmas vêm reorganizando-o em favor dos interesses do grande capital orientado pelos organismos internacionais, que inserem a educação definitivamente na lógica lucrativa do mercado. Este quadro mais geral traz grandes desafios para o conjunto das forças políticas progressistas preocupadas em garantir a estrutura universitária pautada no ensino, pesquisa e extensão de qualidade, incluído aí o Serviço Social e seu projeto ético-político.

Palavras-chave: Educação. Ensino Superior. Universidade. Serviço Social. Projeto ético-político. Marxismo.

\begin{abstract}
The following text is about the transformation that has occurred in the Brazilian university education since the last decade, and the way this change has reorganized such education as to favour the interest of the large capital, which has been guided by international bodies that put education in the profit-oriented logic of the market. This general situation creates great challenges to the political progressive forces which are concerned in guaranteeing the structure of the university education that aims teaching, research and extension courses of good quality. Social Services and its ethical-political project are included in such guarantee of good quality.
\end{abstract}

Keywords: Education. University education. University. Social Services. Ethical-political project. Marxism.

* Mestre em Serviço Social e professor assistente da Universidade Federal dos Vales do Jequitinhonha e Mucuri — Teófilo Otoni/MG — Brasil. E-mail: ricardossmg@yahoo.com.br. 


\section{Introdução}

I

remos realizar alguns apontamentos sobre os desafios postos à formação profissional em Serviço Social e a afirmação de seu projeto ético-político na cena contemporânea, diante do profundo processo de mercantilização que a educação brasileira vem sofrendo, particularmente a partir da década de 1990, que resultou, e ainda continua, por um lado, em uma grande expansão de instituições privadas, e todas as suas consequências, e por outro, em uma avassaladora precarização do ensino público. ${ }^{1}$ Por isto, torna-se urgente a defesa da formação profissional pautada nos pilares do projeto ético-político crítico do Serviço Social.

Algumas questões surgem como desafios a ser enfrentados, tanto pelo conjunto da sociedade brasileira, em relação à defesa radical da educação enquanto um direito socialmente conquistado através da luta dos movimentos sociais e dos trabalhadores, particularmente a defesa de uma universidade pública laica, de qualidade, gratuita e socialmente referenciada, ${ }^{2}$ quanto pelos sujeitos que estão inseridos no escopo profissional do Serviço Social, em defender a manutenção da direção do atual projeto ético-político desta profissão que emerge a partir de $1982,{ }^{3}$ em uma tentativa de aproximar o "fazer profissional" à complexidade contraditória da realidade social.

Dois eixos fundamentais organizam a discussão que segue. No primeiro, alguns apontamentos sobre os impactos que o atual processo de avanço do capital monopolista produz sobre a organização do ensino superior brasileiro, que inicia na década de 1990 no governo Cardoso, e aprofunda-se no governo de Lula da Silva, capitaneado pelo projeto neoliberal. Assim, a organização da

1. Iamamoto (2008) apresenta uma reflexão sobre o significado deste processo para a formação profissional em Serviço Social, o que coloca alguns desafios para o conjunto da categoria profissional na direção de defesa do projeto ético-político, construído ao longo das décadas de 1980 e 1990.

2. Esta concepção de universidade pública é uma bandeira de luta histórica dos movimentos sociais ligados à educação, contrários aos princípios liberais que organizam o mercado e concebem a educação como um serviço que deve ser "livremente" ofertado pela iniciativa privada. Ver Andes, 1981.

3. A aproximação do Serviço Social do referencial teórico crítico expresso pela tradição marxista, que resultou na construção de um projeto de formação profissional ético-político pautado nesta perspectiva, inicia-se no interior da década de 1970 e é tratado por Netto (1991) como "intenção de ruptura". 
política educacional é condicionada à lógica dos organismos financeiros internacionais, através do apoio do Estado nacional.

No segundo momento, a partir deste quadro mais geral, iremos problematizar as especificidades que este processo vem produzindo sobre a formação profissional em serviço social, tendo o atual projeto ético-político como referência a partir da realidade concreta do Estado de Minas Gerais. A perspectiva teórica que orienta esta reflexão é aquela que se vincula à tradição marxista, que toma o fundamento da questão social como ponto de partida para as análises teóricas que consequentemente vinculam-se a uma prática política.

\section{A organização da universidade brasileira inserida na dinâmica do capitalismo monopolista}

A problematização que propomos realizar articula-se ao desenvolvimento dos monopólios enquanto uma fase madura do capitalismo. Isto quer dizer que a lógica de produção dos superlucros invadirá todos os espaços (públicos e privados) e será determinante para as transformações contemporâneas na relação entre Estado e sociedade civil (cf. Netto, 1996).

Esta referência torna-se fundamental para que possamos ter clareza que os processos de reestruturação do ensino superior no Brasil, e os desdobramentos sobre a formação em Serviço Social, articulam-se à complexa dinâmica dos monopólios que submete a reprodução das relações sociais inexoravelmente ao seu princípio de maximizar lucros.

Esta contextualização histórico-social é importante para termos a clareza de que todos os processos econômicos e políticos que ocorrem no bojo das relações sociais estão articulados com o desenvolvimento do capitalismo monopolista, que altera profundamente a dinâmica social, incluindo aí a organização e o significado da universidade brasileira, que passa ser utilizada cada vez mais como instrumento ideológico em favor do pensamento dominante e também para realizar formação estritamente técnica, voltada para os interesses do mercado e processos de formação profissional cada vez mais empobrecidos de uma dimensão humanística e criticidade. 
Foge aos limites deste texto realizar uma problematização sobre o significado histórico das políticas sociais, ${ }^{4}$ inseridas no Estado burguês, ${ }^{5}$ particularmente em sua fase monopolista. Contudo, vale destacar que sua instituição remonta ao processo de luta da classe trabalhadora, por um lado, e a necessidade de busca de hegemonia burguesa, por outro, através da construção de um "pacto" entre as classes sociais, pois, conforme sinaliza Netto (1996, p. 20).

Através da política social, o Estado burguês no capitalismo monopolista procura administrar as expressões da "questão social" de forma a atender às demandas da ordem monopólica, conformando, pela adesão que recebe de categorias e setores cujas demandas incorpora, sistemas de consenso variáveis, mas operantes.

O Estado torna-se um espaço para garantir politicamente a direção econômica pretendida pela burguesia, pois é ocupado por representantes do grande capital monopolista, mesmo possuindo dimensão pública. É no bojo de respostas formuladas por ele (o Estado) que se encontram as políticas sociais, enquanto uma das estratégias de enfrentamento às refrações da questão social. ${ }^{6}$ Isto quer dizer que na fase monopolista, a reprodução das relações burguesas passa a depender da intervenção estatal "contínua, sistemática, estratégica sobre as sequelas da 'questão social', que oferece o mais canônico paradigma dessa indissociabilidade de funções econômicas e políticas que é própria do sistema estatal da sociedade burguesa madura e consolidada" (Netto, 1996, p. 26). O entendimento sobre a complexidade do capitalismo monopolista, enquanto resultado histórico do desenvolvimento burguês, e suas mediações entre a so-

4. A política social é aqui compreendida como um campo de tensões e disputas entre as classes sociais, resultado da movimentação dos trabalhadores, mas também uma estratégia do Estado burguês em construir hegemonia política, econômica e cultural. Existe uma vasta literatura sobre políticas sociais que nos ajuda a pensar sobre o seu significado histórico e sua funcionalidade política e social nestes termos. Podemos citar Faleiros (2000), Berhing (2002) e Berhing e Bochetti (2007).

5. A concepção de Estado utilizada aqui é aquela adotada por Marx e Engels (1996) quando afirmam ser este o "comitê executivo dos negócios da burguesia". Ver Mandel (1985) para uma problematização sobre o aprofundamento desta contradição na lógica monopólica.

6. Sabendo que a questão social é a contradição entre o capital e trabalho, torna-se fundamental compreender seu significado histórico, para realizarmos as devidas mediações com o Estado e a política social, enquanto resposta às suas refrações. Sobre a discussão da questão social na cena contemporânea ver Iamamoto (1998, 2000, 2001), Netto (2001), Pereira (1999, 2001). Uma discussão que se realiza em outra perspectiva teórica encontra-se em Castel (1998). 
ciedade civil e o Estado, por meio de suas funções políticas e econômicas, é que nos dará então as condições concretas para realizar o debate que pretendemos com o devido rigor teórico.

Por isto, a organização e a regulamentação da educação por parte do Estado devem ser compreendidas como um processo de conquista social, travado pelos movimentos sociais e dos trabalhadores, que passam a reivindicar a incorporação de seus direitos na lógica estatal. Assim, o acesso à educação torna-se um direito social e historicamente conquistado, configurando-se, portanto, como uma política social. Entretanto, devemos ter clareza que existe aqui uma articulação entre a institucionalização e a consolidação desse direito, com a dinâmica exposta anteriormente e suas mediações, que por isto subordina-se à lógica de mercantilização das relações sociais e também dos direitos sociais.

Ainda que a educação seja concebida juridicamente como um direito social e garantia fundamental, temos, a partir da década de $1990,{ }^{7}$ uma definitiva abertura da educação para o mercado como um serviço, intensificando a sua dimensão privada e produzindo um rebaixamento do ensino superior público de caráter universitário. Ocorre, então, uma série de processos que "reestruturam" a organização da educação superior, que para além da possibilidade do empresariamento da educação surgem também como possibilidade de outras modalidades de exploração deste serviço, como o ensino a distância, cursos sequenciais e a flexibilização dos currículos. Além disto, torna-se possível a utilização de recursos públicos para garantir o financiamento da educação privada. ${ }^{8}$

Por isto, devemos ter a clareza que os avanços obtidos nesta Constituição expressaram a movimentação social de diversos setores da sociedade em favor de seus interesses, mas que a consolidação dos direitos sociais proposta nesse processo encontrou, a partir de 1990, forte resistência política expressa pelos

7. Uma questão que deve ser considerada neste processo é a promulgação da LDB em 1996 (lei federal n. 9.304/96). O processo de debate em torno da construção da LDB teve, além da proposta aprovada em que o senador Darcy Ribeiro foi o principal mentor, sendo amplamente apoiado pelo governo de FHC, outra conhecida como Projeto Jorge Hage, que se articulou em torno do Fórum Nacional em Defesa da Escola Pública. As divergências destas propostas figuravam sobre o papel do Estado no que se refere à condução da educação. Sobre esta questão, ver Saviani (2008).

8. O Prouni é um exemplo recente desta estratégia, em que o Estado repassa recursos públicos a instituições privadas, supostamente em favor da ampliação e da universalização do ensino superior, mas que mistifica o amparo financeiro ao setor privado da educação em detrimento do investimento na universidade pública. Uma reflexão crítica detalhada sobre este programa pode ser encontrada em Andes-SN (2004). 
princípios neoliberais, ${ }^{9}$ que questiona com veemência crescente o caráter universal das políticas públicas.

Nos termos de Berhing (2003), o que temos no Brasil a partir desse período, e continua no atual governo, ${ }^{10}$ é um processo de contrarreforma do Estado, que significou uma reestruturação do significado das funções públicas estatais. A tentativa, então, de consolidar direitos sociais na sociedade brasileira, após o fim do período conhecido como autocracia burguesa (cf. Netto, 1991), esbarrou nos interesses dos monopólios, que impôs um padrão de acumulação onde não figurava a garantia de políticas públicas universais e ainda passa a reivindicar a abertura para o mercado de serviços sociais. Assim, a tendência na organização das políticas sociais brasileiras, incluindo aí a educação, ${ }^{11}$ será um paulatino rebaixamento da qualidade dos serviços, públicos, por um lado, e a abertura para o mercado desses serviços por outro.

Este é um quadro de desmonte de um padrão de proteção social, que para além de servir aos interesses da burguesia nacional e do capital internacional, nunca garantiu de fato um bem-estar à classe trabalhadora. Nesse sentido, Berhing (2003) irá contrapor-se à ideia de que ocorreu no Brasil uma "reforma" do Estado como apontam os ideólogos liberais, ${ }^{12}$ apresentando o conceito de contrarreforma, que tem enquanto resultado direto a perda de direitos para os trabalhadores e o reordenamento do Estado, conforme aponta a autora

Este argumento fica mais claro em se considerando a história do século XX em nível mundial, na qual o que se pôde chamar de reforma associava-se ao Welfare State - uma reforma dentro do capitalismo, sob a pressão dos trabalhadores, com uma ampliação sem precedentes do papel do fundo público, desencadeando medidas de sustentação da acumulação, ao lado da proteção do emprego e demandas

9. Para uma discussão histórica sobre o neoliberalismo, seus fundamentos econômicos e os desdobramentos deste processo na organização estatal, ver Sader (1995).

10. Para termos uma ideia desse quadro, de janeiro a outubro de 2003 o governo Lula gastou R\$ 86 bilhões no pagamento de dívidas, enquanto reservou $\mathrm{R} \$ 46$ bilhões para investimentos em áreas sociais (cf. Andes-SN, 2004).

11. Sobre esta questão, ver Siqueira e Neves (2006).

12. Luís Carlos Bresser Pereira foi o principal teórico da "reforma" do Estado, à frente do Mare Ministério da Administração e Reforma do Estado - no governo Fernando Henrique Cardoso. Sobre esta questão, ver Bresser Pereira (1998) e Bresser Pereira e Spink (2001). Os ideólogos liberais insistem no termo "reforma" ou "reforma de Estado", necessária para garantir uma pretensa governabilidade. 
dos trabalhadores, viabilizadas por meio dos procedimentos democráticos do Estado de direito, sob a condução da social-democracia. (Berhing, 2003, p. 129)

O termo "reforma" possui uma clara conotação ideológica de cunho neoliberal, sendo amplamente utilizado para justificar a privatização do patrimônio e dos serviços sociais públicos, ocorridos nas últimas décadas. É equivocado considerar como reforma um processo que significou um grande retrocesso para as classes populares e o solapamento das condições de reprodução destas.

Diante do quadro de avanço da lógica dos monopólios de determinismo econômico e a absoluta mercantilização das relações sociais, a proposta de construção de uma universidade pública, laica, de qualidade e socialmente referenciada, balizada no ensino, pesquisa e extensão, como pilares fundamentais de sua estrutura, fica extremamente ameaçada. ${ }^{13}$

A universidade enquanto instituição de ensino deve ser vista como um patrimônio social que se caracteriza por sua dimensão técnico-científica, mas também como formadora e difusora de princípios éticos e uma capacidade crítica de pensar as relações sociais a partir de sua inserção na realidade social e formação de quadros intelectuais. Por isto, ela pode exercer uma função estratégica na formação de identidades sociais e contribuir com o protagonismo no processo da construção de questionamentos críticos e práticas políticas contestatórias.

Então, o projeto de universidade que aqui defendemos é aquele pautado no tripé ensino, pesquisa e extensão, assumindo uma dimensão profundamente pública, e que esta não esteja vinculada à lógica de mercantilização da educação, mas sim ao processo de produção de um conhecimento crítico, que seja capaz contribuir com a transformação social, pois

A dimensão pública das instituições de ensino superior se efetiva simultaneamente pela sua capacidade de representação social, cultural, intelectual e científica. E a condição básica para o desenvolvimento desta representatividade é a capacidade de assegurar uma produção de conhecimento inovador e crítico que respeite a diversidade e o pluralismo, e não simplesmente preencha uma função de reprodução de estruturas, relações e valores, antes acolha os mais diversos elementos que possam

13. É importante destacar que esse é um processo fortemente atravessado por disputa entre projetos de classe sociais. Por isso ainda que o poder político dominante venha realizando profundas transformações na organização da educação em favor do capital, também devemos considerar que existem forças políticas que organizam lutas na direção contrária. 
constituir questionamentos críticos que configurem a universidade como protagonista da evolução histórica da sociedade. (cf. Caderno Andes 2, 2003, p. 15)

Entretanto, o modelo de universidade que se consolidou no Brasil ao longo de seu desenvolvimento histórico pós-1964, na chamada "reforma universitária" de 1968, foi um progressivo empresariamento da educação que resultou na expansão do setor privado ${ }^{14}$ em detrimento do ensino superior público e um conjunto de medidas, "determinadas pelos interesses do capital em converter a educação superior em mercadoria" (Rodrigues, 2007, p. 3). ${ }^{15}$

O debate sobre a universidade brasileira, sua organização e os contornos que esta assume, a partir do quadro de avanço do neoliberalismo e da reestruturação produtiva, impulsionados por um pensamento pós-moderno esvaziado de criticidade ${ }^{16}$ deve estar articulado à lógica de financeirização da economia e à imposição das determinações econômicas dos organismos internacionais que colocam a educação definitivamente na pauta do capitalismo monopolista a partir de 1990, pois segundo Lima (2006, p. 5)

Ao longo da década de 1990, desencadeia-se uma ampliação do espaço privado não somente nas atividades diretamente ligadas à produção econômica, mas também no campo dos direitos sociais conquistados pelas lutas da classe trabalhadora, o que gera um aprofundamento no processo de mercantilização da educação sob a direção política do projeto neoliberal de sociabilidade.

O que passa a ocorrer então, por parte dos governos, é a defesa de que a educação enquanto mercadoria deve ser "universalizada" via mercado, o que entra em rota de colisão com a construção de uma educação pública e de qualidade. $\mathrm{Na}$ verdade, o que temos aqui é um fundamento econômico vinculado

14. Entre 1993 a 2003 houve um crescimento superior a 100\% das instituições privadas no Brasil, sendo que a partir de 1998 o ritmo de crescimento foi de 16\% ao ano (Bin, 2005). Esse processo corresponde exatamente ao período de avanço do projeto neoliberal e a realização de um conjunto de "ajustes" realizados pelo Estado no sentido de adequar a realidade político-econômica com as determinações do grande capital internacional.

15. Este autor tem uma ideia muito interessante que nos ajuda a compreender o significado mercadológico que a educação assume, inserida na lógica do livre mercado e de empresariamento deste direito social que é a "educação-mercadoria" e "mercadoria-educação", que se complementam e servem aos interesses de expansão e de valorização do capital.

16. Ver Harvey (2002). 
aos interesses do grande capital internacional, determinando os contornos da política social pública. O projeto defendido por esses organismos internacionais, defende uma integração dos países periféricos à lógica do capital internacional, sendo a educação [especialmente o ensino superior] entendida pelo pensamento conservador como uma mola propulsora desse processo. No caso do ensino superior, é uma orientação direta do grande capital a partir de 1990, que se promova a redução dos recursos públicos destinados a sua organização, conforme aponta Lima (2006, p. 6), quando nos informa que em um dos seus documentos o Banco Mundial defende que

$\mathrm{Na}$ verdade, pode-se aduzir que o ensino superior não deveria ter mais direitos a utilizar os recursos fiscais disponíveis para a educação em muitos dos países em desenvolvimento, em especial aqueles que ainda não alcançaram acesso, equidade e qualidade adequados aos níveis primário e secundário.

Por isto, o que temos em curso é uma integração periférica que subordina os interesses locais às necessidades de ampliar os superlucros do capital financeiro, comercial e industrial, aprofundando nos termos de Fernandes (1981) um padrão de dominação subalterno e dependente.

Nesta direção, ocorre de forma cada vez mais ampla um alinhamento das instituições de ensino à dinâmica do mercado, o que significa dois movimentos paralelos e concomitantes: a diversificação das fontes de financiamento da educação e uma formação que cada vez mais atenda ao tecnicismo formal do trabalho. Essas questões interessam-nos para pensarmos sobre a formação acadêmico/profissional em Serviço Social e seu projeto ético-político inseridos nesse modelo de universidade, em que a formação apresenta-se cada vez mais esvaziada de uma dimensão crítica.

A partir dessa orientação, a ideia hegemônica presente na condução da educação pelo Estado brasileiro é que a sua "democratização" passa pelo aumento dos investimentos no setor privado em detrimento do público, ou seja, a necessidade de "diversificação" de instituições de ensino é o fator que garantiria o aumento da concorrência e, consequentemente, a elevação da qualidade do serviço, o que representa uma falácia e a imposição dos interesses privados no processo de estruturação da política educacional. ${ }^{17}$

17. Para exemplificar esse processo, destacamos os dados fornecidos por Iamamoto (2008), sobre a expansão do Serviço Social, de que em 2007 havia 253 cursos sendo 18\% em IES públicas e 82\% em IES 
$\mathrm{O}$ aumento de instituições privadas representa claramente um projeto educacional que privilegia os interesses econômicos de grupos que tratam a educação apenas como um negócio. Entretanto, este não o único processo de privatização da educação superior em curso, pois esse movimento também é observado no interior da universidade pública, quando são realizadas "parcerias" com instituições privadas, utilizando, por exemplo, as estruturas mais "flexíveis" das fundações, o que significa o emprego da estrutura físico-acadêmica da universidade em favor de setores privilegiados do mercado.

Além disto, a cobrança de taxas, a redução de gastos com atividades que não são consideradas ligadas à educação, como transporte, alimentação e alojamento, reforçam essa tendência privatizante (cf. Lima, 2006). Contudo, o discurso hegemônico é que todo esse processo de privatização da universidade, quer seja por meio da ampliação de instituições privadas, por meio da transferência de recursos públicos para o setor privado ou ainda a privatização "lenta" da estrutura acadêmico-científica das Ifes, significa uma "democratização" desse nível de ensino.

Nestes termos, a educação transforma-se em uma poderosa estratégia dominante para reforçar sua dominação e contribuir com a construção de uma aceitação coletiva sobre o culto ao mercado, bem como aprofundar uma integração periférica e dependente da lógica do capital monopolista. Nesse processo a educação é entendida como uma possibilidade de "alívio" à pobreza e mobilidade social, ${ }^{18}$ mistificando os reais processos de acumulação da riqueza ${ }^{19}$ e reprodução da desigualdade social. O que se pretende com essa reordenação da universidade brasileira é avançar no processo de financeirização do capital, aprofundando o processo de divisão internacional do trabalho, em que é fundamental a privatização de setores e serviços estratégicos dos países periféricos.

\footnotetext{
privadas. Outro dado relevante é que em apenas três anos de funcionamento, os cursos à distância passaram a oferecer 30\% do total de vagas disponíveis em Serviço Social, o que aponta uma tendência de rebaixamento do ensino superior.

18. Na verdade, o que esse projeto esconde é a necessidade de manter a pobreza em níveis "aceitáveis" e garantir o pleno desenvolvimento do capital, pois a orientação do Banco Mundial é que a superação da pobreza está na "formação dos pobres" por meio da "democratização" da educação. É o mesmo discurso utilizado pelo governo e até algumas centrais sindicais que focam o discurso em torno da ideia de que o fim do desemprego estaria na qualificação dos trabalhadores e no investimento na educação.
}

19. A discussão sobre a acumulação capitalista encontra-se em $O$ capital, no capítulo XXIII (Marx, 2001). 
O perfil então da universidade brasileira na contemporaneidade é uma tendência à formação de alguns grandes centros de excelência em setores estratégicos para o desenvolvimento do capital e atendimento às demandas do mercado, e no outro extremo uma generalização de instituições de ensino, inclusive públicas ${ }^{20}$, com uma formação empobrecida de capacidade crítica para pensar a realidade e rebaixada em qualidade, criando tipos de ensino superior direcionados para estamentos sociais determinados, tendo em vista que

a maioria das entidades privadas tem se pautado na criação de cursos que envolvem pouco risco econômico, como direito, ciências sociais, administração e educação, deixando por conta das universidades públicas os cursos mais caros, como medicina, odontologia, engenharias e ciências naturais, além das atividades mais complexas, como pesquisa e pós-graduação. (Bin, 2005, p. 12)

Isto quer dizer que a tendência é a existência de uma formação "qualificada", mas domesticada à ideologia neoliberal, direcionada para o atendimento das demandas do mercado, e outra generalista e de baixa qualidade, que também cumpre o papel de contribuir com uma bestialização coletiva.

A discussão travada até aqui nos dá um panorama geral sobre o processo de transformações ocorridas na organização da universidade brasileira, a partir dos anos $1990^{21}$ com desdobramentos até os dias de hoje, e sua relação com a dinâmica de expansão do capitalismo, que nos países periféricos orienta-se por determinações econômicas dos grupos dominantes.

Portanto, a partir desse debate, entendemos que outras duas questões devem ser sumariamente problematizadas: a relação entre a formação superior com o mercado e o aprofundamento da contrarreforma educacional imprimida pelo governo Lula. Estas questões são fundamentais para o debate posterior, porque tem rebatimentos sobre o processo de formação em Serviço Social enquanto ensino superior, e implicações em seu projeto ético-político.

O que percebemos nesse debate é que o modelo de "universalização" ao ensino superior, imposto pela lógica monopolista, não é algo que represente um obstáculo ao seu desenvolvimento, porque a educação é incorporada aos negó-

20. O processo pelo qual vem passando as universidades públicas no Brasil, após a implantação do Reuni, é emblemático para exemplificar esse quadro.

21. Refiro-me particularmente neste momento aos dois governos de FHC, em que foi iniciada a privatização da educação no Brasil. 
cios da burguesia como estratégia de valorização do capital, além de promover um adestramento social em relação aos princípios consumistas do mercado a partir de uma formação desqualificada, pois "sob a ótica econômica a tendência é um barateamento da força de trabalho e a criação de um corpo coletivo de trabalhadores nivelados por baixo" (Frigotto, 1984, p. 163).

O padrão de formação superior proposto assume um caráter mercadológico tanto do ponto de vista do atendimento às demandas profissionais quanto da utilização da educação como um negócio lucrativo que não inclui o compromisso ético neste processo formativo. Isto quer dizer que o tipo de conhecimento produzido é funcional ao padrão de consumo e cada vez mais se afasta de uma postura crítica e questionadora de mundo, sendo esse posicionamento assumido inclusive por uma parte considerável dos sujeitos inseridos nas diversas instituições de ensino superior, sejam públicas ou privadas, tendo em vista que "no atual estágio do capitalismo, não serve qualquer trabalhador; são necessários, agora em menor quantidade, trabalhadores mais 'qualificados', que dominem as novas tecnologias, que sejam inovadores e que saibam tomar decisões diante das situações novas" (Bin, 2005, p. 7).

Assim, esse conjunto de transformações sociais que ocorrem no campo político e econômico na dinâmica do capitalismo, impulsionadas por princípios neoliberais, aprofunda o pensamento pós-moderno no interior da universidade brasileira, onde se configura uma crise da razão, que compreende a realidade de forma fragmentada e esvaziada de sua dimensão classista. (cf. Frigotto, 1999). O resultado acadêmico desse processo é a constituição de uma universidade rebaixada intelectual e culturalmente, que atende de maneira muito eficiente aos interesses de expansão do mercado, mas não consegue contribuir de forma significativa com a emancipação humana por meio da educação e da produção de conhecimento.

Cabe-nos ainda destacar que todo o processo de privatização do ensino superior brasileiro, alicerçado nos anos 1990 com os governos $\mathrm{FHC}^{22}$ é aprofundado pelo governo seguinte comandado por Lula da Silva ${ }^{23}$ de forma com-

22. De acordo com o Andes-SN, o governo de FHC implementou a primeira geração de "reformas" e nesta direção o atual governo vem implementando sua segunda geração, solicitadas pelo Banco Mundial, com o objetivo de garantir "apoio ao aperfeiçoamento das finanças públicas" (Andes-SN, 2004, p. 11).

23. Lima (2004) apresenta uma contundente análise sobre a "guinada" que esse governo realizou no que tange à radicalização do projeto neoliberal. 
plementar, sobretudo em relação ao desmonte do modelo de universidade pública pautada nas dimensões do ensino, pesquisa e extensão de forma indissociável.

A condução da política educacional no governo Lula, especialmente aquela relacionada ao ensino superior, não se diferenciou do modelo proposto pelo capital internacional cuja ideia central reside no fato de que a ampliação de vagas no ensino superior passa necessariamente pelo privilegiamento do setor privado, ou seja, uma sintonia fina com as proposições do FMI e Banco Mundial. Nessa direção, o papel determinante desse governo, em relação ao desmonte do ensino público, foi consolidar a regulamentação jurídica iniciada no período anterior.

A política educacional do governo Lula para o ensino superior, aprofundou as chamadas PPPs (parcerias público-privado), o que na prática representa a privatização do ensino público, pois a concepção da política governamental é que as instituições privadas possuem um caráter público e por isto podem receber recursos fiscais para vender seus diplomas. Então, esse projeto político coloca as universidades públicas e gratuitas no mesmo nível das instituições privadas, que são inclusive chamadas a disponibilizar vagas públicas,${ }^{24}$ fortalecendo a ideia de uma esfera pública não estatal e aprofundando a agenda neoliberal para o Brasil. Assim, segundo Lima (2004), o governo Lula apresenta um "neoliberalismo requentado" como proposta para expansão de vagas no ensino superior, utilizando as instituições privadas ou o ensino a distância (EAD). ${ }^{25}$

Uma última reflexão sobre o conjunto de contrarreformas imprimidas por esse governo refere-se ao Reuni, ${ }^{26}$ que pode ser considerado um grande finale dessa segunda geração de "reformas" realizadas na educação brasileira, porque a imposição dessa proposta via decreto desmonta a lógica universitária pautada

\section{Ver nota 8.}

25. Segundo Leher (2004), mais de 70\% das vagas do ensino superior estão nas instituições privadas.

26. Chamado pelo governo de "Programa de Apoio a Planos de Reestruturação e Expansão das Universidades Federais", foi instituído pelo Decreto n. 6.096/07 e apresentado com o objetivo de "criar condições para a ampliação e permanência na educação superior, no nível de graduação, utilizando-se do 'melhor' aproveitamento da estrutura física e dos recursos humanos atualmente existentes nestas instituições" (Andes-SN, 2007, p. 21). Todavia, a liberação de novos recursos para as Ifes está condicionada ao cumprimento das metas pétreas do programa, que é atingir uma relação discente/docente de 18/1 e 90\% de aprovação. 
no trinômio ensino, pesquisa e extensão e rebaixa a capacidade intelectual da universidade pública ao nível tecnicista e empobrecido das exigências do mercado. $^{27}$

Essa proposta de expansão do ensino público vem ocorrendo em condições de infraestrutura precárias, condições de trabalho inadequadas, quadros de docentes e técnico-administrativos insuficientes, ausência de políticas de assistência estudantil e plano de qualificação docente. Deste modo, o processo em curso vem sendo realizado de forma extremamente truculenta, via conselhos universitários ou acordos entre o MEC e reitorias, e sem a efetiva participação democrática da comunidade acadêmica. A tendência é que o resultado dessa expansão não signifique o acesso à educação superior pública de qualidade e a garantia de permanência dos estudantes.

A "reestruturação" pretendida pelo governo Lula para a universidade pública é a realização de uma formação universitária a partir de ligeiros ciclos básicos nos moldes da excludente Universidade Nova, ${ }^{28}$ que visa atender a uma histórica bandeira de luta dos movimentos sociais que é a universalização do ensino superior, mas que nesses moldes ocorre de forma extremamente esvaziada de condições concretas para uma ampliação adequada do ensino superior.

O que parece é que para alcançar as metas estabelecidas pelo governo, será necessário promover uma descaracterização da proposta universitária fundada na produção de um conhecimento que se complementa por meio de ensino, pesquisa e extensão, além de aligeiramento na formação e profunda precarização do trabalho docente por intermédio da institucionalização do "Banco de Professor-equivalente" como estratégia para rebaixar a qualidade da formação e fragilizar o movimento sindical docente.

O professor Roberto Leher nos ajuda a pensar sobre os caminhos que a sociedade brasileira deve trilhar diante desse quadro de ataque à universidade pelo atual governo, quando aponta que

27. O coroamento desse projeto está agora na proposta de ingresso a universidade via Enem, que produz uma concorrência desigual pelas vagas disponíveis e dificultará ainda mais o acesso ao ensino público dos cidadãos com menores possibilidades financeiras.

28. A UFBA apresentou a proposta intitulada de Universidade Nova em 2006, que propunha uma formação generalista a um grande contingente de estudantes a partir de "ciclos básicos" curtos, para posteriormente realizar uma formação específica. O projeto da Universidade Nova pode ser acessado por meio do endereço <http://www.anped11.uerj.br $>$. 
Após a quebra da expectativa do caráter transformador do governo de Lula da Silva, assentada em esperanças desprovidas de materialidade, é preciso reconstruir as bases e os fundamentos que possam ensejar ideias que, de fato, abram horizontes capazes de, nas lutas assegurar um lugar de destaque para a universidade brasileira. (Leher, 2004, p. 16)

Fica claro, a partir desta discussão, que a universidade no Brasil vem sofrendo, desde a década de 1990, um sistemático processo de ataques à sua dimensão pública que trata a educação como uma mercadoria, privilegiando as instituições privadas, além de investir contra o modelo universitário pautado na indissociabilidade do ensino, pesquisa e extensão. Por isso, o desafio posto aos movimentos sociais é construir uma unidade em torno da defesa radical do ensino público.

Doravante, iremos problematizar sobre as implicações do processo apontado, referente à reestruturação da universidade brasileira alinhada com os princípios de mercado, para a formação em Serviço Social e seus desdobramentos em seu projeto ético-político construído nas últimas duas décadas.

\section{A defesa do projeto ético-político do Serviço Social diante do contexto de mercantilização do ensino superior no Brasil}

A partir da discussão travada até aqui, podemos afirmar que o processo de privatização do ensino superior brasileiro operado pelos governos Cardoso e Lula, e orquestrado pelo grande capital transformou a venda de diplomas superiores em um negócio altamente lucrativo, que se desenvolve vertiginosamente a partir da integração funcional de instituições públicas e privadas.

Nesse sentido, temos a incorporação do ensino superior na dinâmica do capitalismo, produzindo um tipo de capitalismo universitário, ou seja, o direcionamento da produção do conhecimento científico à funcionalidade do mercado. Por isto, qualquer construção intelectual científica ${ }^{29}$ que não esteja alinhada com

29. Aqui estou considerando conhecimento científico tanto aquele que se relaciona com as áreas duras da ciência (exatas, biológicas, naturais e tecnológicas), como as ciências humanas e sociais aplicadas, onde está inserido o Serviço Social. 
essa proposta pós-moderna terá uma grande batalha a ser travada no campo das ideias, que certamente resultará em práticas políticas. Seguramente podemos incluir nessa arena política o Serviço Social e seu projeto ético-político.

Esta parece ser, então, uma questão central para ser discutida no interior do Serviço Social: a defesa radical da direção crítica do projeto ético-político do Serviço Social diante do quadro de mercadização da educação superior. Sabemos que as instituições de ensino superior (universitárias ou não, públicas ou privadas) constituem uma das possibilidades de inserção profissional e, portanto, não devem deter a exclusividade sobre este debate, mas assume grande importância quando pensamos que esse é o espaço responsável pela condução da formação profissional.

Trata-se, portanto, de demarcar um posicionamento político em favor da universidade pública e de qualidade enquanto princípio, o que não significa um narcisismo profissional, mas uma responsabilidade intelectual, compromisso com princípios éticos e um vanguardismo no interior da universidade e na relação com outras áreas do conhecimento, para enfrentar o projeto neoliberal para ensino superior brasileiro, e, em uma perspectiva mais ampliada, também latino-americano.

O desenvolvimento do Serviço Social no Brasil, ao longo do século XX, ${ }^{30}$ representa indiscutivelmente um giro de seu projeto profissional na direção de uma tradição de pensamento fundada no materialismo histórico enquanto referencial teórico hegemônico, que indubitavelmente requisita uma prática política contestatória e crítica. O Serviço Social, enquanto profissão, constitui-se a partir das dimensões [indissociáveis] técnica e teórico-metodológica, que se articula a seu caráter interventivo no trato das expressões da questão social, o que implica também uma orientação ético-política articulada a uma práxis social crítica.

Assim, um projeto ético que represente a libertação do homem da alienação produzida pelo trabalho e seu processo de coisificação das relações sociais significa enfrentar com radicalidade a contradição posta nesse modo de produ-

30. Atualmente existe uma vasta bibliografia que trata do desenvolvimento histórico e teórico-metodológico do Serviço Social (brasileiro e latino-americano) enquanto "profissão inscrita na divisão sociotécnica do trabalho". Podemos citar apenas, para ilustrar, Castro (1989), Martinelli (1995), Netto (1991 e 1996), Montaño (2007), Iamamoto (1995 e 2008). Além disso, a publicação Serviço Social \& Sociedade tornou-se uma referência fundamental para a produção intelectual dessa categoria profissional. 
ção que acumula a riqueza socialmente produzida, pois de acordo com Barroco (2008a, p. 37):

Na sociedade alienada, diz Marx, o indivíduo busca no dinheiro as formas de satisfação de suas necessidades egoístas; torna-se cada vez mais pobre como homem e isso faz do trabalhador um ser pobre em necessidades e formas de satisfação, uma vez que seus sentidos e capacidade se desumanizam.

Nesse sentido, o que se denominou projeto ético-político, construído a partir da virada para os anos 1980 e aprofundado nas décadas seguintes, vinculou-se fortemente com uma capacidade de pensar a realidade a partir do método crítico-dialético, em que toma o fundamento econômico da questão social como ponto de partida para a realização das diversas análises sobre a realidade social. ${ }^{31}$

Esta observação torna-se importante para termos clareza que como qualquer projeto político, aquele que se constrói em torno dos sujeitos presentes no escopo profissional do Serviço Social, também é permeado por divergências e disputas, ou seja, esta direção intelectual e ética não garante por si só uma prática política em uma perspectiva contestadora. Sendo assim, não podemos equivocadamente pensar o projeto profissional do Serviço Social em voga como um corpo homogêneo e sem relevos teórico-práticos distintos, pois a direção social que foi construída ao longo desse processo tem que ser cotidianamente defendida e (re)afirmada como uma opção política e teórico-metodológica por seus sujeitos. Esta análise nos sugere pensar sobre uma direção hegemônica construída historicamente, e não em uma homogeneidade profissional.

Uma análise mais profunda e precisa sobre essa questão poderia nos mostrar que a tendência de ruptura, apontada por Netto (1996) no processo de maturidade intelectual do Serviço Social, se atualiza em nosso tempo por meio de uma falsa aceitação do marxismo enquanto direção social. Isto equivale a interpretações rasas e esvaziadas do método dessa matriz teórica, que aparece como um marxismo empobrecido de sua dimensão crítica.

31. É bom lembrar que Netto (1996) identifica em suas análises, no interior do processo de renovação do Serviço Social, desenvolvido e radicalizado durante a década de 1970, uma tendência denominada por ele "intenção de ruptura", que naquele momento apontava para uma contraposição ao projeto profissional tradicional vinculado à ética cristã e ao pragmatismo liberal. 
Esta é uma questão central nesse debate, porque o que vamos perceber em alguma medida é um reforço ao pragmatismo e ao burocratismo desconectados de uma capacidade crítica de pensar o real a partir de seu antagonismo, que estão presentes nos processos de formação profissional. Daí a necessidade de garantir articulação político-intelectual dos sujeitos políticos do Serviço Social, de modo que possamos enfrentar com competência o espraiamento dessa tendência no contexto de mercantilização do ensino superior.

Desta forma, pensar a formação em Serviço Social na atual realidade, inserida na dinâmica de organização e privatização do ensino superior brasileiro, conforme apresentado anteriormente, é posicionar-se com radicalidade teórica e política contrária ao avanço do endeusamento ao mercado e em favor da democratização da dimensão pública do Estado. Nestes termos, Netto (2004), em artigo que problematiza o Serviço Social a partir do governo Lula, que naquele momento já dava sinais que não pretendia alterar a condução da política econômica anterior, chamada de herança maldita, coloca uma questão central para o conjunto da categoria que se reatualiza diante do atual quadro da universidade brasileira, quando afirma que "trata-se, em suma, da prova a que estão sendo submetidos, num processo que seguramente se aprofundará e agravará, os setores profissionais que formularam e promoveram o que já se consagrou como o 'projeto ético-político' do Serviço Social brasileiro" (p. 6).

O aprofundamento desse debate passa pela discussão sobre os fundamentos éticos do Serviço Social, para que possamos confrontar a proposta de formação, que tem desdobramentos sobre a prática profissional, com o quadro universitário atual que assume contornos claramente pós-modernos. A partir desse confronto, poderemos pensar os dilemas e desafios profissionais para que coletivamente possamos assegurar a direção social profissional conquistada historicamente.

Os fundamentos ontológicos do atual projeto ético-político profissional, como parte da renovação operada na profissão e expressos no código de ética de 1993, realiza um movimento de romper com o tradicionalismo existente nas décadas anteriores e ocorre no calor das movimentações da década de 1980 em favor da redemocratização da sociedade brasileira. Temos então a afirmação de um compromisso profissional articulado com a realidade dos trabalhadores e luta pelos direitos sociais e humanos, balizados por princípios emancipatórios, como equidade, justiça social, democracia plena e liberdade enquanto conquista humana. 
A opção de construção do eixo central para o projeto profissional parte do entendimento de que a ética, enquanto atividade humana, relaciona-se com a ontologia do ser social ${ }^{32}$ que se materializa e constrói valores no processo de trabalho. Por isto, Barroco (2008b, p. 201), ao analisar os fundamentos ontológicos do código de ética profissional, afirma:

Ao indicar a centralidade do trabalho na (re)produção da vida social, o Código revela a base objetiva de constituição das ações ético-morais: as capacidades que, desenvolvidas a partir da práxis, objetivam a sociabilidade, a consciência, a liberdade e a universalidade do ser humano-genérico. Em função dessas capacidades objetivas explicitam-se os valores éticos fundamentais: liberdade, equidade e justiça social, articulando-os à democracia, à cidadania.

Torna-se então fundamental para a afirmação de uma direção profissional crítica enfrentar o processo de coisificação e alienação impregnado à sociabilidade burguesa, de modo que seja possível contribuir com a emancipação do homem e o desmascaramento das relações sociais mistificadas pelo véu do dinheiro e das requisições imediatistas do mercado. No bojo do Serviço Social, esse processo apenas será levado adiante no campo da tradição marxista. Por isto, a reivindicação de radicalização desse projeto está articulada ao conjunto de demandas da classe trabalhadora, que inclui um aprofundamento do caráter democrático e público do Estado (cf. Ferreira, 1999).

O Serviço Social, enquanto profissão "socialmente inserida na divisão sociotécnica do trabalho e uma especialização do trabalho coletivo" (Iamamoto, 1995), historicamente foi demarcando seu campo de atuação nos espaços públicos e privados, conquistando sua legitimidade social e reconhecimento junto aos usuários, construindo dessa maneira um projeto profissional que nos dias de hoje extrapola a dimensão meramente técnico-operativa, pois

Os projetos profissionais apresentam a autoimagem de uma profissão, elegem os valores que a legitimam socialmente, delimitam e priorizam os seus objetivos e funções, formulam os requisitos (teóricos, institucionais e práticos) para o seu exercício, prescrevem normas para o comportamento dos profissionais e estabe-

32. Para o aprofundamento desta discussão para a compreensão crítica do processo de produção e reprodução social, ver Lukács (1978 e 1979), Netto e Braz (2006) e Lessa (2002). 
lecem as balizas da sua relação com os usuários de seus serviços, com as outras profissões e com as organizações e instituições sociais, privadas e públicas (entre estas, também e destacadamente com o Estado, ao qual coube, historicamente, o reconhecimento jurídico dos estatutos profissionais). (Netto, 1999, p. 95)

A defesa dos princípios que balizam o projeto ético-político do Serviço Social não podem assumir um caráter liberal conservador ou interpretações ideologizadas frequentemente utilizadas para justificar um reformismo social, pois, para o pensamento liberal, princípios como liberdade, justiça social e democracia estão articulados à privatização da propriedade e acumulação da riqueza.

A tendência desse pensamento é considerar a igualdade entre os indivíduos como mero fundamento jurídico, em detrimento da contradição das relações sociais fundadas na exploração do trabalho. Portanto, "a liberdade defendida pelo liberalismo supõe a desigualdade; vincula a posse de bens materiais à felicidade, numa sociedade fundada na propriedade privada dos meios de produção e do trabalho" (Barroco, 2008b, p. 203). Nesta direção, os valores liberais burgueses são abstrações que precisam ser apoderadas pelo conjunto da classe trabalhadora, para por meio de suas lutas buscar a concretização efetiva da panaceia burguesa.

O Serviço Social, enquanto profissão que possui dimensão eminentemente interventiva e caráter "educativo", está inserido nos mais diversos espaços institucionais sociais e em contato direto com a classe trabalhadora. Este deve ter então clareza sobre o significado político da ética burguesa para opor-se a ela em seu trabalho cotidiano. Sobre essa questão torna-se pertinente ressaltar que um sólido processo de formação profissional qualificado nos moldes universitário pode contribuir com o alargamento da capacidade crítica de apreensão da realidade. Por isto, o quadro atual de rebaixamento do ensino superior coloca sérios desafios à afirmação da direção crítica construída no Serviço Social.

Devemos apontar também a importância entre a articulação dos projetos societários e os projetos profissionais, sabendo que há um significado social de qualquer profissão no interior das relações sociais. Este é marcadamente definido por uma capacidade de emitir respostas e enfrentar problemáticas que se relacionam com um mix entre a funcionalidade do mercado e as necessidades objetivas humanas. Esta consideração torna-se importante para percebermos que o projeto ético-político defendido nesta reflexão é aquele que tem um vínculo com o caráter contraditório presente nas classes sociais. 
Todo posicionamento ético parte de escolhas a partir da conquista da liberdade, motivo pelo qual a afirmação de uma direção profissional crítica deve ser o resultado coletivo da aproximação da realidade com uma práxis parametrada na ontologia do ser social como referência. A opção ética do Serviço Social contida em seu projeto, que transborda o conjunto de normas e relações propostas em um código, relaciona-se com valores e princípios que objetivam a emancipação do gênero humano e choca-se com a lógica burguesa, vinculada estritamente à organização de um processo de trabalho que se destina à produção e à acumulação de riquezas.

A tradição intelectual burguesa conduz à produção de um conhecimento rígido e engessado que se torna instrumento estratégico e fundamental para a reprodução ampliada das relações sociais, pois como nos mostra Barroco (2009, p. 14) "a sociedade burguesa tende a suprimir e/ou negligenciar as abordagens críticas, humanistas e universalistas, donde a desvalorização do conhecimento filosófico, o apelo ao conhecimento instrumental, ao utilitarismo ético, ao relativismo cultural e político". Fica claro que a proposta de ensino superior implementada atualmente possui estreita articulação com essa forma de conceber a realidade.

A discussão colocada até aqui nos remete a algumas questões, que se transformam em dilemas para o Serviço Social diante do quadro de mercantilização do ensino superior, por um lado, e a resistência dos sujeitos profissionais para manter a direção social construída, por outro. Sabemos que esta é uma tarefa de extensa envergadura e requisitará grande capacidade intelectual e política para debruçar-se sobre esse quadro e construir alternativas coletivas, incluindo nesse campo o Serviço Social.

A forma de organização do ensino superior brasileiro que vem se estruturando ataca frontalmente o projeto de universidade fundada no ensino, pesquisa e extensão, impondo a construção de um conhecimento acrítico e funcional às demandas do mercado. Neste sentido, a formação em Serviço Social, que ao longo dos últimos trinta anos construiu um acúmulo teórico-prático crítico, transforma-se em uma referência contra-hegemônica e passa a ser alvo de ataques do capital universitário (o que não é uma exclusividade do Serviço Social) no sentido de descaracterizar sua proposta ético-política.

Isso ocorre à medida que o processo de formação profissional sofre rebatimentos dos processos pedagógicos implementados, que afetam a organização 
das disciplinas e seus conteúdos, o estágio, a pesquisa, incluindo a pós-graduação, a extensão, a organização do processo de elaboração das monografias finais de curso, além da capacitação docente e condições de trabalho dos profissionais envolvidos nos diversos cursos de graduação e pós-graduação. Outra questão que vem produzindo rebatimentos extremamente negativos sobre a formação profissional é o seu aligeiramento e a modalidade de ensino a distância.

$\mathrm{O}$ trato cotidiano das diversas expressões da questão social tem sido fortemente influenciado por uma formação que tem na capacidade crítica sua orientação teórico-prática. Por isso a ameaça posta pela contrarreforma em curso está na descaracterização dessa direção formativa, por meio da organização de um modelo de ensino superior que não consegue produzir um conhecimento capaz de romper com a alienação liberal, e em vez disto, reforça o tecnicismo instrumental como o único caminho para a formação superior, o que, nos termos de Pinto (2007), poderá produzir uma tendência à desprofissionalização da graduação em Serviço Social.

Os dados sobre a expansão do ensino superior em sua modalidade privada, particularmente os cursos de Serviço Social, ${ }^{33}$ não deixam dúvidas que vem ocorrendo um franco processo de mercantilização da educação que certamente tende a afetar a formação em Serviço Social em seu viés crítico. Para termos clareza que esse processo vem se aprofundando, segundo dados governamentais, ${ }^{34}$ apenas a região Sudeste do Brasil conta com 120 cursos de Serviço Social, sendo que quarenta destes encontram-se no estado de Minas Gerais e apenas três são públicos. Por isto, o posicionamento político em favor do projeto ético-político do Serviço Social torna-se extremamente urgente, no sentido de buscar a construção de uma universidade efetivamente pública e de qualidade.

Torna-se necessário, então, que o conjunto das forças políticas preocupadas em consolidar e aprofundar as conquistas intelectuais do Serviço Social trave uma luta cotidiana e que tenha como base o referencial crítico, porque todo esse quadro vem interferindo nos diversos processos formativos, promovendo tendencialmente um rebaixamento de sua qualidade, o que poderá pro-

33. Dahmer (2007) apresenta dados que demonstram essa expansão, quando afirma que, em 2007, $89,28 \%$ das IES eram privadas, sendo 92,6\% IES não universitárias. Sobre a particularidade do Serviço Social, segundo essa mesma autora, até 1994 eram 74 cursos em todo o Brasil, e entre 1995 e 2002 foram criados 49 , representando um aumento de $66,21 \%$.

34. Disponível em: <http://sinaes.inep.gov.br/sinaes/>. Acesso em: 22 out. 2009. 
duzir uma prática profissional que não se conecta com a contradição do real e, pior do que isto, reforce os pressupostos liberais mistificados por uma aparente criticidade.

\section{Considerações finais instigantes}

A partir do debate realizado e diante da complexidade das questões apresentadas, não cabe realizar apontamentos conclusivos, mas considerações que indicam a necessidade de aprofundamento da discussão de modo que possamos contribuir com a defesa de uma universidade pública e de qualidade e a afirmação do atual projeto ético-político do Serviço Social enquanto direção profissional.

Percebemos claramente que o Estado brasileiro a partir dos anos 1990 tem organizado sua política educacional em conformidade com as determinações dos organismos internacionais, particularmente o Banco Mundial e o FMI. Cabe destacar que esse processo iniciou-se no governo FHC, mas vem sendo aprofundado de maneira vertiginosa pelo mandato de Lula da Silva, por meio do aumento de instituições privadas, o desmonte da lógica indissociável das universidades públicas, pautada no ensino, pesquisa e extensão, e a abertura para o mercado da possibilidade de ensino a distância, inclusive de graduação.

O resultado dessa opção política assumida pelas elites políticas tem sido uma reestruturação radical do ensino superior no Brasil. $\mathrm{O}$ que temos visto então é um processo de progressiva expansão do ensino superior - "crescimento para menos" - por meio do empresariamento da educação, e também de uma descaracterização da universidade pública, que passa a ser gerenciada a partir de uma lógica privada. Assim, os processos de formação profissional voltam-se para atender o mercado e suas demandas imediatistas e técnicas, esvaziados de uma dimensão crítica e orientados por uma direção pós-moderna.

Surge, então, um tipo de capitalismo universitário ou acadêmico, em que o ensino superior, além de cumprir sua função tradicional de valorizar o capital, assume uma posição estratégica na reprodução das relações burguesas e uma funcionalidade que se volta para o mercado, na medida em que passa a controlar e a direcionar a produção de um tipo de conhecimento científico que atinge todas as áreas do conhecimento, mercantilizado e sintonizado com as demandas das corporações industriais. 
A construção da educação enquanto direito social, entendida como um componente estratégico para a transformação social, deve estar articulada com as lutas da classe trabalhadora e dos movimentos sociais, mas o que vem ocorrendo é o movimento coordenado pela esfera estatal de desconstruí-la enquanto direito social, considerando-a como bem público e, como tal, sem distinção entre a esfera privada ou pública.

Este projeto para a educação descaracteriza o ensino superior e sua capacidade de produzir conhecimento reflexivo e articulado com a complexidade contraditória do real, pois pensa a formação superior a partir de uma lógica terciária (educação pós-secundária), e não universitária, que praticamente restringe esse segmento ao ensino descolado da pesquisa e da extensão, e atravessa o espaço acadêmico com a lógica do mercado e suas determinações. As propostas do governo para a política educacional põem em questão a noção da educação de qualidade como um direito universal.

Essa postura política do Estado, que se mistifica a partir do discurso de que deste modo opera-se a universalização e a democratização do ensino, na verdade reforça a desigualdade social e a reprodução de relações tipicamente capitalistas, além de oferecer aos capitalistas mão de obra de baixo custo. A retórica de que a universalização da educação, via sua abertura ao setor privado, representa mobilidade social e alívio à pobreza, aprofunda uma integração subalterna dos países periféricos à lógica de financeirização do capital e acirramento da divisão internacional do trabalho.

Deste modo, a defesa radical do projeto ético-político do Serviço Social, orientado por seus princípios e construído por seus sujeitos ao longo do último quartel do século XX, significa a afirmação da universidade pública, de qualidade, laica, gratuita e socialmente referenciada, fundada no ensino, na pesquisa e na extensão enquanto pilares básicos para a produção de um conhecimento que tenha como compromisso a emancipação humana.

Os desafios não são pequenos, requisitarão grande envergadura teórica e radicalidade política, e nem pode ser uma atribuição exclusiva do Serviço Social, o que representaria um grande equívoco, como já ocorreu no passado. Ao contrário, deve ser assumido pelo conjunto da classe trabalhadora como um requisito para a conquista de sua cidadania plena, onde o ensino superior possui relevância estratégica para a produção de um conhecimento que se articule não com as demandas do mercado, mas com a contradição da realidade social. 
Todavia, o Serviço Social, por conta de sua tradição crítica, pode tornar-se um importante protagonista nesse processo.

Finalmente, mas sem nenhuma pretensão de ser conclusivo, pretendemos oferecer uma contribuição para o processo de fortalecimento da universidade pública e a defesa do projeto ético-político do Serviço Social pautado em uma formação de qualidade, além de afirmar uma posição política contrária ao neoliberalismo e todas suas investidas sobre a educação brasileira.

Artigo recebido em abr./2010 - Aprovado em jun./2010

\section{Referências bibliográficas}

ANDES-SN. Cadernos Andes. Florianópolis, n. 2, 1981.

A contrarreforma da educação superior: uma análise do Andes-SN das principais iniciativas do governo Lula da Silva. GTPE. ANDES-SN: Brasília, 2004.

. As novas faces da reforma universitária do governo Lula e os impactos do PDE sobre a educação superior. Cadernos Andes. Brasília, n. 25, 2007.

BARROCO, Maria Lúcia S. Ética: fundamentos sócio-históricos. São Paulo: Cortez, 2008a. (Biblioteca básica do Serviço Social, v. 4).

. Ética e Serviço Social: fundamentos ontológicos. 6. ed. São Paulo: Cortez, $2008 \mathrm{~b}$.

. Fundamentos éticos do Serviço Social. Curso de especialização à distância. Serviço Social: Direitos sociais e competências profissionais. Brasília: Abepss, 2009.

BERHING, Elaine Rossetti. Política social no capitalismo tardio. 2. ed. São Paulo: Cortez, 2002.

. Brasil em contrarreforma: desestruturação do Estado e perda de direitos. São Paulo: Cortez, 2003.

BERHING Elaine Rosseti; BOSCHETTI, Ivanete. Política social: fundamentos e história. 2. ed. São Paulo: Cortez, 2007.

BIN, Daniel. Subordinação funcionalista ao capitalismo neoliberal e mercantilização do ensino superior. In: $28^{\mathrm{a}}$ REUNIÃO ANUAL DA Anped, 2005, Caxambu. Anais. Rio 
de Janeiro: Anped — Associação Nacional de Pós-Graduação e Pesquisa em Educação, 2005. p. 1-17.

BRESSER PEREIRA, Luís Carlos. Reforma do Estado para a cidadania: a reforma gerencial brasileira na perspectiva internacional. São Paulo: Ed. 34; Brasília: Enap, 1998. p. 225-250.

; SPINK, Peter Kevin. Reforma do Estado e administração pública gerencial. 4. ed. Rio de Janeiro: Editora FGV, 2001.

CASTEL, Robert. As metamorfoses da questão social: uma crônica do salário. Petrópolis: Vozes, 1998.

CASTRO, Manuel Manrique. História do Serviço Social na América Latina. São Paulo: Cortez, 1989.

DHAMER PEREIRA, Larissa. Mercantilização do ensino superior e formação profissional em Serviço Social: em direção a um intelectual colaboracionista? Revista Ágora: Políticas Públicas e Serviço Social. ano 3, n. 6, abr. 2007. Disponível em: <http://www. assistentesocial.com.br>. Acesso em: 18 jan. 2010.

FALEIROS, Vicente de Paula. A política social do Estado capitalista. 8. ed. São Paulo: Cortez, 2000.

FERNANDES, Florestan. Capitalismo dependente e classes sociais na América Latina. 3. ed. Rio de Janeiro: Zahar, 1981.

FERREIRA, Ivanete Salete Boschetti. As políticas brasileiras de seguridade social: assistência social. In: Programa de Capacitação em Serviço Social e política social. Brasília: Cead, 1999. Módulo 3.

FRIGOTTO, Gaudêncio. A produtividade da escola improdutiva. 2. ed. São Paulo: Editora Autores e Associados, 1984.

Educação, crise do trabalho assalariado e do desenvolvimento: teorias em conflito. In: FRIGOTTO, Gaudêncio (Org.). Educação e crise do trabalho: perspectivas de final de século. 3. ed. Petrópolis: Vozes, 1999.

HARVEY, David. Condição pós-moderna. 11. ed. São Paulo: Loyola, 2002.

IAMAMOTO. Marilda Villela. Questão social e Serviço Social. In: O Serviço Social na contemporaneidade: trabalho e formação profissional. São Paulo: Cortez, 1998.

Renovação e conservadorismo no Serviço Social. 5. ed. São Paulo: Cortez, 2000. 
IAMAMOTO. Marilda Villela. A questão social no capitalismo. In: Temporalis. Associação Brasileira de Ensino Pesquisa em Serviço Social. Ano 2, n. 3. Brasília: ABEPSS, Grafline, 2001.

. Serviço Social em tempo de capital fetiche: capital financeiro, trabalho e questão social. 2. ed. São Paulo: Cortez, 2008.

; CARVALHO, Raul de. Relações sociais e Serviço Social no Brasil: esboço de uma interpretação histórico-metodológica. 10. ed. Rio de Janeiro: Cortez, 1995.

LEHER, Roberto. A (contra)reforma universitária do governo Lula e o fim das fronteiras entre o público e o privado. In: NEVES, Lúcia Maria Wanderley (Org.). Reforma universitária do governo Lula: reflexões para o debate. São Paulo: Xamã, 2004.

LESSA, Sérgio. Mundo dos homens: trabalho e ser social. São Paulo: Boitempo, 2002.

LIMA, Kátia. Reforma universitária do governo Lula: o relançamento do conceito de público não estatal. In: NEVES, Lúcia Maria Wanderley (Org.). Reforma universitária do governo Lula: reflexões para o debate. São Paulo: Xamã, 2004.

. Organismos internacionais: o capital em busca de novos campos de exploração lucrativa. Caderno Especial, n. 30, 2006. Disponível em: <www.assistentesocial.com. br>. Acesso em: 30 nov. 2009.

LUKÁCS, George. As bases ontológicas da atividade humana. In: Revista Temas de Ciências Humanas. São Paulo: Editora Ciências Humanas, 1978. n. 4.

. Ontologia do ser social: os princípios ontológicos fundamentais de Marx. São Paulo: Editora Ciências Humanas, 1979.

MANDEL, Ernest. O capitalismo tardio. 2. ed. São Paulo: Nova Cultural, 1985.

MARTINELLI, Maria Lúcia. Serviço Social: identidade e alienação. 4. ed. São Paulo: Cortez, 1995.

MARX, Karl. O capital: crítica da economia política: livro I. Tradução de Reginaldo Sant'Anna. 17. ed. Rio de Janeiro: Civilização Brasileira, 2001.

; ENGELS, Frederich. O manifesto do Partido Comunista. Rio de Janeiro: Paz e Terra, 1996.

MONTAÑO, Carlos. A natureza do Serviço Social: um ensaio sobre sua gênese, a "especificidade" e sua reprodução. São Paulo: Cortez, 2007.

NETTO, José Paulo. Ditadura e Serviço Social: uma análise do Serviço Social no Brasil pós-64. São Paulo: Cortez, 1991.

Capitalismo monopolista e Serviço Social. 2. ed. São Paulo: Cortez, 1996. 
NETTO, José Paulo. A construção do projeto ético-político do Serviço Social frente à crise contemporânea. In: Programa de Capacitação em Serviço Social e política social. Brasília: Cead, 1999. Módulo 1.

. Cinco Notas a Propósito da "Questão Social". In: Temporalis. Revista da Associação Brasileira de Ensino Pesquisa em Serviço Social, ano 2, n. 3. Brasília, ABEPSS, Grafine, 2001.

A conjuntura brasileira: o Serviço Social posto à prova. Serviço Social \& Sociedade. São Paulo, n. 79, p. 5-26, 2004.

; BRAZ, Marcelo. Economia política: uma introdução crítica. São Paulo: Cortez, 2006. (Biblioteca básica do Serviço Social, v. 1).

PEREIRA, Potyara Amazoneida P. A metamorfose da questão social e a reestruturação das políticas sociais. In: Programa de Capacitação em Serviço Social e política social. Brasília: Cead, 1999. Módulo 1.

Questão social, Serviço Social e direitos de cidadania. Temporalis. Revista da Associação Brasileira de Ensino Pesquisa em Serviço Social. Brasília, ano 2, n. 3, 2001.

PINTO. Marina Barbosa. A contra-reforma do ensino superior e a desprofissionalização da graduação em Serviço Social. Revista Ágora: Políticas Públicas e Serviço Social, ano 3, n. 6, abr. 2007. Disponível em: <http://www.assistentesocial.com.br>. Acesso em: 30 nov. 2009.

RODRIGUES, José. Os empresários e a educação superior. Campinas: Autores e Associados, 2007.

SADER, Emir. A hegemonia neoliberal na América Latina. IN: SADER, Emir; GENTILI, Pablo (Orgs.). Pós-neoliberalismo: as políticas sociais e o Estado democrático. Rio de Janeiro: Paz e Terra, 1995.

SAVIANI, Demerval. A nova lei da educação. LDB: trajetória, limites e perspectivas. 11. ed. Campinas: Autores Associados, 2008.

SIQUEIRA, Ângela C. de; NEVES, Lúcia Maria W. (Orgs.). Educação superior: uma reforma em processo. São Paulo: Xamã, 2006. 